\title{
INTERDISCIPLINARIDADE E FORMAÇÃO CONTINUADA: O DIÁLOGO DE CONHECIMENTOS
}

\author{
Deise Nanci de Castro Mesquita*
}

\section{ReSUMo}

O Projeto de Extensão Comunitária de Educação Continuada em Línguas Estrangeiras (PECEC-LEs) desenvolve diferentes atividades pedagógicas que visam a contribuir para a formação de alunos e professores de braille, espanhol, inglês e libras. A proposta interdisciplinar praticada pelo PECEC-LEs é de revisão e não de reforma educacional, e está fundamentada na compreensão de que: 1) o raciocínio é analítico e relacional, não pode ser considerado como um procedimento redutor da realidade; 2) a formação é um processo complexo e singular, não pode ser pensada como algo a ser adquirido de forma fragmentada e mecânica; e 3) a educação escolar é um processo formal de cooperação, de encontro de indivíduos, de cruzamento de experiências, saberes e visões de mundo, não pode ser reduzida apenas ao encontro de disciplinas. Este projeto de extensão comunitária se materializa no diálogo, na busca de uma formação continuada que reitere o estatuto de identidade do cidadão e o seu compromisso social.

Palavras-Chave: diálogo, formação, interdisciplinaridade.

\section{Interdisciplinarity and formal education: dialogue and knowledge}

\section{Abstract}

The staff that integrates the academic project PECEC-LEs (Projeto de Extensão Comunitária de Educação Continuada em Línguas Estrangeiras) develops different pedagogical activities, which aim at contributing to the education of students and teachers of Braille, Spanish, English and Libras (Língua Brasileira de Sinais). The main purpose of PECECLEs is to re-think practices with participants, rather than introducing new proposals for them and to their classrooms. Three basic concepts lead the activities developed at PECEC-LEs: 1) as thinking is analytical and relational, it is not taken as a simple (de)codification of reality; 2) as education is a singular and complex process, it is not acquired by means of mechanical and fragmented approaches; and 3) as school education is a formal process of cooperation and inter-relationship, exchanging of experiences and different views of the world, it is not reduced to a simple presentation of (inter)disciplines. The main objective of this presentation is to discuss the concept of interdisciplinary that guides the Project, which has to do with dialogue, inclusive education and the recognition and exchanging of different knowledge as ways of regaining humanity.

KEY worDs: dialogue, education, interdisciplinary.

* Professora de línguas estrangeiras da Universidade Católica de Goiás. E-mail: deisnanc@br.turbo.com.br 


\section{Revista Solta a Voz, v. 16, n. 1}

\section{INTRODUÇão}

O Projeto de Extensão Comunitária de Educação Continuada em Línguas Estrangeiras (PECEC-LEs) é um projeto de integração entre docentes de educação básica e ensino superior, discentes licenciandos, estagiários e monitores de pesquisas para a educação continuada em línguas estrangeiras: braille, espanhol, inglês e libras. Ele já tem dez anos de implantação. No período de 1994 a 2000, era o Núcleo de Apoio Pedagógico do Projeto Nacional de Integração entre Universidades e Escolas de $1^{\circ}$ e $2^{\circ}$ graus para a melhoria do ensino de inglês (NAP/GO do PIMEI) e, a partir de 2002, estabelece-se como PECEC-LEs.

O Projeto coordena módulos semanais (presenciais e a distância) de avaliação do trabalho docente e preparação de projetos para a prática pedagógica reflexiva e interativa de ensino fundamental e médio. Oferece cursos semestrais de curta duração, seminários, conferências e palestras. Realiza encontros anuais de estudo e pesquisa sobre questões teórico-práticas da linguagem e da aquisição de línguas, além de produzir materiais didáticos impressos e virtuais.

O objetivo geral do PECEC-Les, levando em conta a formação continuada no que se refere ao lingüístico e ao pedagógico, é promover um ambiente de pesquisa-ação integral e sistêmica de base antropopedagógica, que se caracteriza pela implicação, pelo diálogo e pela expressão dos atores em presença, sustentada na disposição argumentativa e no caráter dialogado da situação social. Como objetivos específicos, tem-se: debruçar-se sobre a prática docente, para reconhecimento de sua incessante necessidade de transformação e buscar formas de atender às suas exigências reais diárias; viabilizar o aprimoramento da fluência oral e escrita do docente e discente, em língua materna e estrangeira; e discutir sobre as questões ligadas à educação inclusiva e aos ciclos de desenvolvimento humano.

\section{O PRINCÍPIO INTERDISCIPLINAR dA Proposta É O DE MANTER UM DIÁLOGO DE CONHECIMENTOS}

A prática pedagógica do PECEC-LEs fundamenta-se no diálogo, uma categoria potencialmente agressiva que se refere ao conceito de batalha, que problematiza a democratização da diferença, que enfatiza a reciprocidade como um contrato interlocutório, que apresenta as 
contradições que acercam os sujeitos e suas questões como elementos fundantes da práxis. É, pois, um projeto de formação continuada que toma em conta o pensamento crítico-reflexivo da proposta emancipatória de Freire (1989, p. 41), que entende a prática educativa consubstanciada na discussão e na busca constante de unidade na diversidade de interesses não-antagônicos. Para o autor, a história se faz na práxis, na luta, no conflito, no antagonismo, na divergência.

Trata-se de um processo educativo que se contrapõe a modelos hierarquizantes do conhecimento, em que a pedagogia freiriana é tomada como parte do quadro maior da educação e não meramente como uma abordagem, um método ou uma técnica. Concerne ao processo de ensino e aprendizagem das disciplinas como uma relação estabelecida entre educandos, com vistas não apenas à transmissão de conhecimentos específicos, mas fundamentalmente à construção de subjetividades, crenças e valores que definem o significado de ser humano. Nas palavras de Freire (1995, p. 63):

É vivendo, não importa se com deslizes, com incoerências, mas disposto a superá-los, a humildade, a amorosidade, a coragem, a tolerância, a competência, a capacidade de decidir, a segurança, a eticidade, a justiça, a tensão entre paciência e impaciência, a parcimônia verbal, que contribuo para criar, para forjar, a escola feliz, a escola alegre. A escola que é aventura, que marcha, que não tem medo do risco, por isso que recusa o imobilismo. A escola em que se pensa, em que se atua, em que se cria, em que se fala, em que se ama, se adivinha, a escola que apaixonadamente diz sim à vida. E não à escola que emudece e me emudece.

Esta disposição argumentativa restitui o caráter dialogado da situação social, orienta a sua prática no equacionamento dos problemas encontrados, no acompanhamento e na avaliação das ações desencadeadas em função destes questionamentos. Portanto, não diz respeito à dinâmica de transformação de uma dada situação em uma outra desejada ou à busca por novos modelos de desenvolvimento alternativo.

Realmente, a pretensão desta proposta é (re)criar alternativas ao desenvolvimento, a outras formas de (re)conhecimento, pois, tal como nos ensina Giroux (1991, p. 234-235), o processo de formação deve servir para retratar o equívoco que tem sido tomar o mundo globalizado 


\section{Revista Solta a Voz, v. 16, n. 1}

como sendo supostamente hegemônico, ao invés de considerar a contemporaneidade deste processo de globalização como uma forma de demarcação e legitimação de novas formas de diálogo, solidariedade e cultura marcadas pela pluralidade e heterogeneidade de saberes:

What is important to stress is the recognition that a critical postmodernism needs to provide educators with a more complex and insightful view of the relationship between culture, power, and knowledge. When linked with the language of democratic public life, the notions of difference, power, and specificity can be understood as part of a public discourse that broadens and deepens individual liberties and rights through rather than against a radical notion of democracy. (Giroux, 1991, p. 234-235)

A realidade, ininterruptas movimentações de informações resultantes de grandes avanços técnico-científicos exige que a formação seja também dinâmica, independente e transformadora, e que os órgãos envolvidos no processo saibam trocar o conforto da certeza que sustenta os conteúdos (teóricos e práticos) das disciplinas específicas, pela instabilidade tão imprevisível quanto inimaginável dos questionamentos reais.

Essa prática interdisciplinar leva em consideração o fato de que o conhecimento científico não é apenas o armazenamento de ocorrências, mas também a reflexão de como a história dialética foi e é obtida, avaliada e atualizada. Toma o processo educativo como algo imprevisível, sem garantias de causas e efeitos sempre semelhantes em todos os aprendizes, e auto-organizável, que obedece a uma ordem própria dentro da própria desordem. Suscita, pois, o reconhecimento de que, em razão da ação de qualquer força (metodologia, estratégia ou técnica de aquisição), esse complexo sistema entra em estado de desequilíbrio e, pela ação dirigida em sentido inverso, restabelece o estado de equilíbrio, fazendo com que, embora semelhantes os resultados desses movimentos, nunca sejam idênticos. É uma retomada de conceitos e princípios que definem a influência e a responsabilidade de todos na desconstrução de conhecimentos baseados em um mundo supostamente objetivo, de estrutura pré-determinada, com relações unívocas entre causa e efeito. Nas palavras de Sampaio (2002, p. 64-65),

significa permear todas as atividades acadêmicas (sala de aula, laboratórios, monografias, estágios, pesquisas etc.) com a pergunta que a ética faz sobre a sua relevância no processo de produção e de socialização do conhecimento 
Revista Solta a Voz, v. 16, n. 127

[...] Nestas relações, deverá haver a convivência dos saberes sistematizadoacadêmicos e popular, tendo como conseqüência a produção do conhecimento resultante do confronto com a realidade regional ou nacional.

Portanto, o princípio interdisciplinar que orienta a prática do PECEC-LEs leva em conta a combinação de fatores biocognitivo-afetivos do ensino e aprendizagem. Parte do entendimento de que o raciocínio configura-se em um objeto dinâmico e ao mesmo tempo organizado, que esse processo se dá em uma relação complexa, dinâmica, inusitada e contingencial, e que a organização dessa estrutura se realiza entre a ordem total e o caos. Em outras palavras, tem a ver com a compreensão de que a aquisição de conhecimentos depende de inúmeros fatores que atuam como uma força que perturba uma situação estável e que provoca os movimentos, as transformações no sistema psíquico.

Essa atitude interdisciplinar difere, pois, das concepções que entendem o aprendiz como sendo aquele que é bem-sucedido, porque sabe como utilizar suas próprias estratégias para aprender. Logo, é contrária a toda visão positivista cuja equação (consciência + autonomia $=$ sucesso) é dada em termos de causa e efeito e que entende o conhecimento como uma representação direta da realidade objetiva, um produto intelectual a ser passado e adquirido. Enfim, assemelha-se às práticas que fazem a analogia entre a estrutura que rege os sistemas complexos e os diferentes estilos de raciocínio, e que concluem que, para se aprender, resta ao aprendiz deixar que a zona estável de seu sistema seja perturbada e, daí, que os efeitos significativos desse processo de aquisição possam ser gerados. Nas palavras de Paiva (2003, p. 1),

a combinação desses fatores, no entanto, não é determinista no sentido de que, um conjunto $X$, na proporção $Y$ de variáveis, geraria uma aprendizagem bem-sucedida ou malsucedida. O ser humano é imprevisível, e mudanças e ajustamentos diferentes podem ocorrer em situações semelhantes.

Por isso, a interdisciplinaridade que resulta desse diálogo de conhecimentos distancia-se das práticas que sustentam: 1) a existência de um único modelo efetivo de ensino e aprendizagem para todo e qualquer aprendiz; 2) o conhecimento como sendo um mero produto do acúmulo de informações repassadas ao longo dos tempos; 3) a autonomia como sendo um conceito limitado à responsabilidade do sujeito 
28 Revista Solta a Voz, v. 16, n. 1

sobre sua própria aprendizagem; e 4) a educação escolar formal reduzida apenas ao encontro de disciplinas científicas.

\section{As atividades PEdAgógicas do PECEC-LEs: CONHECIMENTOS INTERDISCIPLINARES}

Embora as ações planejadas pela equipe que compõe o PECECLEs busquem atender às especificidades de cada grupo, todas possuem as características gerais de promover reuniões de programação, de estudo, de preparação de material didático, de avaliação e de reestruturação permanente do Projeto. Tais atividades pedagógicas são constantemente reestruturadas e desenvolvidas em dois formatos: convencional e virtual. Para o ano letivo de 2005/1, estão previstas as seguintes atividades presenciais: 1) Libras - Metodologia de Ensino e Aprendizagem para Surdos; 2) Braille - Leitura; 3) Producción de materiales didácticos; 4) Fonética y fonología; 5) Conversación en lengua española; 6) La enseñanza-aprendizaje del léxico; 7) La enseñanza intercultural del español; 8) La utilización de las películas en las clases; 9) Refletindo Sobre Teoria e Prática - Inglês; 10) Criação e Produção de Atividades de Inglês; 11) ARTSLIT: inglês em uma abordagem comunicativa; 12) Filmes, Ensino e Aprendizagem de Inglês; 13) Phonetics and Fluency; 14) Ciclos e Aula de Inglês; 15) English Advanced - Módulo III; 16) English Intermediate - Módulo I e 17) Avaliação e Produção de Materiais Didáticos de Inglês a partir dos Temas Transversais - Módulo II; e uma atividade a distância: English Virtual Course - Módulo IV.

Os cursos presenciais apresentam as seguintes características metodológicas: 1) discussão e escolha de temas a serem trabalhados durante o semestre; 2) programação mensal das atividades escritas e orais contemplando os temas escolhidos; 3) prática e avaliação semanal das atividades propostas; 4) socialização e discussão mensal das atividades desenvolvidas; e 5) produção e apresentação semestral de material escrito e oral em encontro científico. O objetivo geral é que o espaço desses encontros no PECEC-LEs constitua-se em um ambiente privilegiado para a prática de uma metodologia de pesquisa-ação integral e sistêmica de base antropopedagógica, segundo Morin (2004, p. 133), que se caracterize pela implicação, pelo diálogo e a expressão dos atores em presença e que seja constituída, pois, de ciclos de reajuste. Para isso, 
Revista Solta a Voz, v. 16, n. 129

os pesquisadores participantes ou os atores pesquisadores devem ficar atentos ao processo de comunicação essencial em toda PAIS. Devem se preparar ao diálogo de igual para igual, entre pesquisadores em título (encarregados do projeto) e atores pesquisadores (freqüentemente, profissionais especializados) para chegarem a uma compreensão mútua. Essa atenção aos outros exige uma capacidade de viver a incerteza e de reconhecer o caráter único de cada situação. Assim, o próprio processo de pesquisa-ação, com participação cooperativa e sistêmica, inscreve-se em situações dinâmicas, em que as coisas estão em contínua mudança, ou em reconstrução. (Morin, 2004, p. 133)

O curso não-presencial serve de pólo organizador de um grupo de pessoas interessadas no ensino e aprendizagem de língua inglesa mediado por computador. Privilegia a educação continuada e socializada de professores e alunos e potencializa atitudes autônomas de ensino e aprendizagem do idioma, em sua função verbal oral e escrita. As metas são a elaboração, a utilização, a avaliação e a reformulação de metodologias - abordagens, técnicas, materiais didáticos e ferramentas - que atendam também à modalidade virtual de ensino. A produção oral e escrita dos participantes, apresentada semanalmente via correio eletrônico, mensalmente em fórum de debates e semestralmente em videoconferência, indica os problemas e as possibilidades de uma metodologia que privilegia outras formas de abordar e organizar materiais didáticos. Os dados coletados e analisados servem de referência para a confecção do Programa Permanente de Curso de Línguas Estrangeiras On-Line.

\section{CONSIDERAÇÕES FINAIS}

Estas diferentes atividades propostas pela equipe que integra o PECEC-LEs são interdisciplinares na medida em que: 1) tratam de consolidar a consciência da ausência como presença possível da transformação, da imaginação utópica que interroga sobre a natureza e a qualidade ética da sociedade; e 2) permitem a criação de outros locais e novas articulações diferentes dos adotados na constituição do cânone ocidental, enquanto um processo de marginalização, supressão e subversão de epistemologias, tradições culturais e opções sociais e políticas alternativas.

Enfim, a referência interdisciplinar que norteia este projeto de educação continuada em línguas estrangeiras está atrelada ao desconforto e à indignação que obrigam o sujeito a interrogar criticamente 
30 Revista Solta a Voz, v. 16, n. 1

sobre a falência da miragem do desenvolvimento e a buscar alternativas teoricamente fundadas nas respostas dadas até agora a estas interrogações. Nas palavras de Santos (2001, p.30),

nesta forma de reconhecimento, conhecer é reconhecer, é progredir no sentido de elevar o outro da condição de objeto à condição de sujeito. Esse conhecimento-reconhecimento é o que designo por solidariedade. Estamos tão habituados a conceber o conhecimento como um princípio de ordem sobre as coisas e sobre os outros que é difícil imaginar uma forma de conhecimento que funcione como princípio de solidariedade. No entanto, tal dificuldade é um desafio que deve ser enfrentado. Sabendo nós hoje o que aconteceu às alternativas propostas pela teoria crítica moderna não nos podemos contentar com um pensamento de alternativas. Necessitamos de um pensamento alternativo de alternativas.

\section{REFERÊNCIAS}

FREIRE, P. Professora sim tia não. São Paulo: Olho d’Água. 1995. dos, 1989.

Pedagogia: diálogo e conflito. São Paulo: Cortez-Autores Associa-

GIROUX, H. Postmodernism and educational criticism. New York: University of Minnesota Press, 1991.

MORIN, A. Pesquisa-ação integral e sistêmica: uma antropopedagogia renovada. Tradução: Thiolllent, M. Rio de Janeiro: DP\&A, 2004.

PAIVA, V. Modelo fractal de aquisição de linguas. Disponível em: < http:// www.veramenezes.com >. Acesso em: $1^{\circ}$ dez. 2003.

SAMPAIO, J. A gestão e a avaliação da extensão: um desafio para a comunidade acadêmica. In: ENCONTRO NACIONAL DE EXTENSÃO E AÇÃO, 9., 2002, Florianópolis, SC. Anais... Florianópolis, SC: Universidade da Região de Joinville, 2002.

SANTOS, B. A crítica da razão indolente: contra o desperdício da experiência. São Paulo: Cortez, 2001.

Recebido em: 15 fev. 2005

Aceito em: 10 maio 2005 